\title{
An assessment of CALIOP polar stratospheric cloud composition classification
}

\author{
M. C. Pitts ${ }^{1}$, L. R. Poole ${ }^{2}$, A. Lambert ${ }^{3}$, and L. W. Thomason ${ }^{1}$ \\ ${ }^{1}$ NASA Langley Research Center, Hampton, Virginia 23681, USA \\ ${ }^{2}$ Science Systems and Applications, Incorporated, Hampton, Virginia 23666, USA \\ ${ }^{3}$ Jet Propulsion Laboratory, California Institute of Technology, Pasadena, California 91109, USA \\ Correspondence to: M. C. Pitts (michael.c.pitts@nasa.gov)
}

Received: 15 August 2012 - Published in Atmos. Chem. Phys. Discuss.: 20 September 2012

Revised: 28 January 2013 - Accepted: 25 February 2013 - Published: 15 March 2013

\begin{abstract}
This study assesses the robustness of the CALIOP (Cloud-Aerosol Lidar with Orthogonal Polarization) polar stratospheric cloud (PSC) composition classification algorithm - which is based solely on the spaceborne lidar data - through the use of nearly coincident gas-phase $\mathrm{HNO}_{3}$ and $\mathrm{H}_{2} \mathrm{O}$ data from the Microwave Limb Sounder (MLS) on Aura and Goddard Earth Observing System Model, Version 5 (GEOS-5) temperature analyses. Following the approach of Lambert et al. (2012), we compared the observed temperature-dependent $\mathrm{HNO}_{3}$ uptake by PSCs in the various CALIOP composition classes with modeled uptake for supercooled ternary solutions (STS) and equilibrium nitric acid trihydrate (NAT). We examined the CALIOP PSC data record from both polar regions over the period from 2006 through 2011 and over a range of potential temperature levels spanning the $15-30 \mathrm{~km}$ altitude range. We found that most PSCs identified as STS exhibit gas phase uptake of $\mathrm{HNO}_{3}$ consistent with theory, but with a small temperature bias, similar to Lambert et al. (2012). Ice PSC classification is also robust in the CALIOP optical data, with the mode in the ice observations occurring about $0.5 \mathrm{~K}$ below the frost point. We found that CALIOP PSCs identified as NAT mixtures exhibit two distinct preferred modes which reflect the fact that the growth of NAT particles is kinetically limited. One mode is significantly out of thermodynamic equilibrium with respect to NAT due to short exposure times to temperatures below the NAT existence temperature, $T_{\mathrm{NAT}}$, with $\mathrm{HNO}_{3}$ uptake dominated by the more numerous liquid droplets. The other NAT mixture mode is much closer to NAT thermodynamic equilibrium, indicating that the particles have been exposed to temperatures below $T_{\mathrm{NAT}}$ for extended periods of time. With
\end{abstract}

a few notable exceptions, PSCs in the various composition classes conform well to their expected temperature existence regimes. We have a good understanding of the cause of the minor misclassifications that do occur and will investigate means to correct these deficiencies in our next generation algorithm.

\section{Introduction}

Polar stratospheric clouds (PSCs) play two essential roles in the springtime chemical depletion of ozone at high latitudes (Solomon, 1999). First of all, PSC particles serve as catalytic sites for heterogeneous chemical reactions that transform stable chlorine and bromine reservoir species into highly reactive ozone-destructive forms. These heterogeneous reactions are most efficient on liquid supercooled ternary $\left(\mathrm{HNO}_{3} / \mathrm{H}_{2} \mathrm{SO}_{4} / \mathrm{H}_{2} \mathrm{O}\right)$ solution (STS) PSC particles because of the larger total surface area and higher reaction efficiencies associated with STS (Lowe and MacKenzie, 2008). Secondly, if PSC particles grow sufficiently large, they can remove gaseous odd nitrogen from the lower stratosphere through gravitational sedimentation, which slows the reformation of the chlorine reservoirs and prolongs the ozone depletion process. This so-called denitrification is caused primarily by solid nitric acid trihydrate (NAT) PSC particles because the high number density $\left(\sim 10 \mathrm{~cm}^{-3}\right)$ of STS particles limits them to sub-micron sizes with concomitantly small fall speeds. Thus, it is important to better understand particle composition in order to capture PSC processes more 
accurately in global models used to predict the future state of the stratospheric ozone layer.

Spaceborne observations from the CALIOP (CloudAerosol Lidar with Orthogonal Polarization) lidar on the CALIPSO (Cloud-Aerosol Lidar and Infrared Pathfinder Satellite Observations) satellite, which commenced in June 2006, are providing a rich new dataset for studying PSCs (e.g., Noel et al., 2008; Pitts et al., 2007, 2009, 2011; Noel and Pitts, 2012). CALIPSO is part of the NASA A-train satellite constellation (Stephens et al., 2002), flying in formation with the Aqua, CloudSat, and Aura satellites. Pitts et al. (2009) (hereafter referred to as P09) developed an approach for both detection and composition classification of PSCs observed by CALIOP. The P09 composition classification algorithm infers PSC composition based on theoretical calculations of 532-nm backscatter and depolarization for non-equilibrium external mixtures of liquid (binary $\mathrm{H}_{2} \mathrm{SO}_{4} / \mathrm{H}_{2} \mathrm{O}$ or STS) and solid NAT or ice particles, which ground-based and airborne lidar measurements indicate are quite common (e.g., Biele et al., 2001; Toon et al., 2000).

In the absence of simultaneous in situ particle observations, the CALIOP PSC composition classification scheme can be evaluated by comparison with other remote measurements that provide information on particle composition. In one such study, Höpfner et al. (2009) reported a high degree of consistency between CALIOP PSC compositions for the 2006-2007 Antarctic and 2006/07-2007/08 Arctic winters and those derived from MIPAS (Michelson Interferometer for Passive Atmospheric Sounding) data on the Envisat spacecraft. A finding of particular note was that for PSCs in which the spectral signature of NAT was detected by MIPAS, about $90 \%$ of coincident CALIOP data were classified as mixed liquid/NAT clouds, lending credence to the CALIOP composition classification scheme.

A recent study of the early 2008 Antarctic PSC season by Lambert et al. (2012) demonstrated that one can also gain valuable insight into PSC processes by analyzing the CALIOP data in combination with nearly coincident gas phase $\mathrm{HNO}_{3}$ and $\mathrm{H}_{2} \mathrm{O}$ measurements from the Microwave Limb Sounder (MLS) on the Aura satellite. Since $\mathrm{HNO}_{3}$ and/or $\mathrm{H}_{2} \mathrm{O}$ are the major constituents of all PSC particles (STS, NAT, and $\mathrm{H}_{2} \mathrm{O}$ ice), tracking their uptake by PSCs as a function of temperature using MLS data provides constraints on particle composition and volume density. In this study, we follow the approach of Lambert et al. (2012) to analyze CALIOP PSC observations from 2006-2011 in conjunction with the Aura MLS data and temperature analyses from the Goddard Earth Observing System Data Assimilation System (GEOS-5 DAS). Comparison of the observed uptake of $\mathrm{HNO}_{3}$ by CALIOP PSCs with modeled uptake for equilibrium STS and NAT indicates how well PSCs in the various composition classes conform to expected temperature existence regimes and offers some insight into the kinetics of PSC growth. The overarching goals of this paper are to assess the robustness of the P09 composition classifica- tion algorithm and identify potential improvements that can be implemented in the next generation algorithm.

\section{Datasets}

\subsection{CALIOP PSC data}

CALIOP was launched aboard the CALIPSO satellite in April 2006 and became operational in June 2006. CALIPSO is in a $98.2^{\circ}$ inclination orbit which provides excellent coverage over the polar regions of both hemispheres with measurements up to about $82^{\circ}$ latitude. CALIOP is a dual-wavelength $(532 \mathrm{~nm}$ and $1064 \mathrm{~nm})$, polarization-sensitive $(532 \mathrm{~nm})$ elastic backscatter lidar (Winker et al., 2009). The polarization sensitive measurements allow discrimination between spherical (liquid) and non-spherical (solid) particles. A more detailed description of CALIOP and its on-orbit performance can be found in Hunt et al. (2009) and information on calibration of the CALIOP data can be found in Powell et al. (2009). The most current information regarding the CALIOP data products and their proper usage can be found in the CALIPSO Data Users Guide (http://www-calipso.larc. nasa.gov/resources/calipso_users_guide/).

The P09 PSC detection algorithm uses both the CALIOP $532-\mathrm{nm}$ scattering ratio $\left(R_{532}\right.$, the ratio of total to molecular backscatter, e.g., Cairo et al., 1999) and the 532-nm perpendicular backscatter coefficient $\left(\beta_{\text {perp }}\right)$. As described in P09, the CALIOP stratospheric data are smoothed to a common 5$\mathrm{km}$ horizontal by $180-\mathrm{m}$ vertical grid prior to PSC detection to account for the change in spatial resolution of the Level 1B CALIOP data products at $20.2 \mathrm{~km}$ altitude. PSC detection is then performed using a successive horizontal averaging $(5,15,45,135 \mathrm{~km})$ procedure that ensures that optically thicker clouds (e.g., ice and fully developed STS) are found at the finest possible spatial resolution while also enhancing the detection of tenuous PSCs (e.g., low number density NAT mixtures) that are found only through additional averaging. A CALIOP observation is assumed to be a PSC if either $\beta_{\text {perp }}$ or $R_{532}$ exceeds a statistical threshold defined as the median plus four median deviations (five median deviations for 5-km averaging) of the background aerosol ensemble (those data at temperatures above $200 \mathrm{~K}$ ). The P09 algorithm also introduced a scheme for classifying PSCs by composition based on comparison of CALIOP aerosol depolarization ratio $\left(\delta_{\text {aerosol }}\right.$, the ratio of the perpendicular to parallel components of aerosol backscatter, e.g., Cairo et al., 1999) and inverse scattering ratio $\left(1 / R_{532}\right)$ with theoretical optical calculations for equilibrium STS and representative nonequilibrium external liquid-solid particle mixtures, assuming $50 \mathrm{hPa}$ atmospheric pressure and nominal mixing ratios of 10 ppbv $\mathrm{HNO}_{3}$ and 5 ppmv $\mathrm{H}_{2} \mathrm{O}$. As subsequently modified by Pitts et al. (2011) (hereafter referred to as P11), CALIOP PSCs are now separated into six composition classes: three classes of liquid/NAT mixtures, with Mix 1, Mix 2, and Mix 
2-enhanced denoting increasingly higher NAT number density/volume; STS (which also includes low number densities of NAT particles whose optical signature is masked by the much more numerous STS droplets at cold temperatures); $\mathrm{H}_{2} \mathrm{O}$ ice; and mountain wave ice, the latter having high particle number densities $\left(\sim 10 \mathrm{~cm}^{-3}\right)$ but concomitantly small (1.0-1.5 $\mu \mathrm{m}$ radius) particles (e.g., Fueglistaler et al., 2003). Figure 1 shows a composite 2-D histogram of CALIOP PSC observations from the 2009-2010 Arctic winter in the $\delta_{\text {aerosol }}$ vs. $1 / R_{532}$ coordinate system, with the boundaries of the six P11 composition classes denoted by the black lines.

For this study, we have slightly modified the P09/P11 composition classification scheme to ensure a more robust separation between STS PSCs and PSCs containing non-spherical particles. PSC detection and composition classification were done independently in the P09/P11 algorithm, so it is possible that a PSC detected through an enhancement in $\beta_{\text {perp }}$, a clear indicator of non-spherical particles, could be classified as STS because the calculated $\delta_{\text {aerosol }}$ value fell in the STS composition regime due to measurement noise. Conversely, a PSC detected strictly through an enhancement in $R_{532}$ with no detectable enhancement in $\beta_{\text {perp }}$ could be classified as a liquid/NAT mixture or ice because the derived $\delta_{\text {aerosol }}$ fell outside the STS regime due to noise. We correct these inconsistencies for the present study by including two additional constraints: (1) PSCs detected through an enhancement in $\beta_{\text {perp }}$ will be classified as NAT mixtures or ice PSCs (depending on the magnitude of $R_{532}$ ) regardless of the calculated $\delta_{\text {aerosol }}$ value (similar to the constraint imposed by Lambert et al., 2012), and (2) PSCs exhibiting no enhancement in $\beta_{\text {perp }}$ will be classified as STS regardless of the calculated $\delta_{\text {aerosol }}$ value.

The boundaries drawn between the composition classes do not reflect the inherent uncertainty in the CALIOP measurements. Hence, the boundaries are actually "fuzzy" and toggling between adjacent composition classes on short spatial scales may be simply due to measurement noise rather than a true change in composition. We have analyzed a large ensemble of data from the 2009-2010 Arctic winter to better characterize the crosstalk between composition classes due to measurement noise. We found that there is some overlap in the probability density functions (PDFs) of $\beta_{\text {perp }}$ for STS and NAT mixture classes, analogous to the overlap in

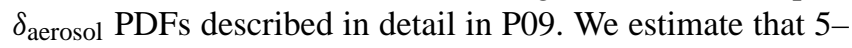
$6 \%$ of PSCs classified as STS may actually be NAT mixtures, whereas only $1-2 \%$ of PSCs classified as NAT mixtures may actually be STS. We have a high degree of confidence in the classification of ice PSCs; median uncertainties in $1 / R_{532}$ and $\delta_{\text {aerosol }}$ for ice PSCs are around 0.03 and 0.13 , respectively, and therefore it is unlikely that ice PSCs would be misclassified as NAT mixtures due to measurement noise. We have less confidence in the separation of NAT mixtures into Mix 1, Mix 2, and Mix 2-enhanced classifications. Median uncertainties in $1 / R_{532}$ and $\delta_{\text {aerosol }}$ for NAT mixture PSCs as a whole are around 0.1 and 0.2 , respectively, so that tog-

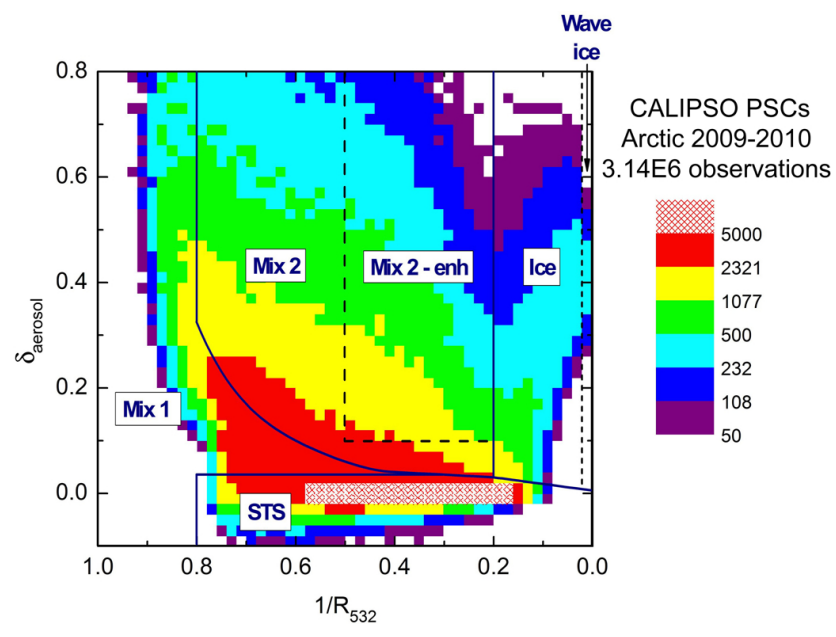

Fig. 1. Composite 2-D histogram of all CALIOP PSC observations during the 2009-2010 Arctic winter in the $\delta_{\text {aerosol }}$ vs. $1 / R_{532}$ coordinate system, with the solid black lines denoting the boundaries of the six PSC composition domains defined by P09 and the dashed boxes denoting the domains of the two new composition sub-classes defined by P11. The histogram bin size is $0.02 \times 0.02$ (both unitless) and the color scale indicates the number of cloud observations falling within each bin.

gling between adjacent mixture classes due to random noise is likely.

Temperature profiles at each CALIOP measurement location are also included in the CALIOP Level 1 data files. The temperature data have been interpolated to the CALIOP Level 1 measurement locations from the Goddard Earth Observing System Model, Version 5 (GEOS-5) six-hourly gridded analyses $\left(0.5^{\circ}\right.$ latitude $\times 0.67^{\circ}$ longitude) (Rienecker et al., 2008). To match the standard PSC grid, the GEOS-5 data are smoothed to the 5-km horizontal resolution and interpolated to the $180-\mathrm{m}$ vertical grid.

\subsection{Aura MLS}

The Aura MLS detects thermal microwave emission from the Earth's limb (Waters et al., 2006) along the line-of-sight in the forward direction of the Aura spacecraft flight track. Vertical scans made from the Earth's surface to a $90 \mathrm{~km}$ tangent height every $24.7 \mathrm{~s}$ provide a total of 3500 vertical profiles per day with a horizontal along track spacing of 1.5 degrees $(165 \mathrm{~km})$ and nearly global latitude coverage from $82^{\circ} \mathrm{S}-$ $82^{\circ} \mathrm{N}$. The limb radiance measurements are inverted using a 2-D optimal estimation retrieval (Livesey et al., 2006) to yield atmospheric profiles of temperature and composition in the vertical range $8-90 \mathrm{~km}$ (Livesey et al., 2006). For the vertical range relevant for PSCs, the MLS version 3.3 measurements (Livesey et al., 2011) have typical single-profile precisions of 4-15\% for $\mathrm{H}_{2} \mathrm{O}$ (Read et al., 2007; Lambert et al., 2007) and 0.7 ppbv for $\mathrm{HNO}_{3}$ (Santee et al., 2007). Vertical and horizontal along-track resolutions are $3.1-3.5 \mathrm{~km}$ 
and $180-290 \mathrm{~km}$ for $\mathrm{H}_{2} \mathrm{O}$, and $3.5-5.5 \mathrm{~km}$ and $400-550 \mathrm{~km}$ for $\mathrm{HNO}_{3}$.

Since Aura flies in formation with CALIPSO in the Atrain satellite constellation, CALIOP and MLS measurement tracks are closely aligned with spatial and temporal differences less than $10 \mathrm{~km}$ and $30 \mathrm{~s}$ after a repositioning of the Aura satellite in April 2008 and about $200 \mathrm{~km}$ and 7-8 min prior to 2008 (see Lambert et al., 2012). To produce a colocated dataset, the MLS gas species measurements are interpolated to the CALIOP PSC grid using a weighted average of the two nearest MLS profiles. In addition, ancillary meteorological parameters from the Aura MLS Derived Meteorological Products (DMPs) (Manney et al., 2007), such as equivalent latitude, are also mapped onto the PSC grid.

\section{Data analyses}

Our basic approach is to combine CALIOP PSC observations with nearly coincident Aura MLS gas species measurements and GEOS-5 temperature analyses to track the uptake of gas phase $\mathrm{HNO}_{3}$ as a function of temperature. Comparing the observed $\mathrm{HNO}_{3}$ uptake with theoretical equilibrium $\mathrm{HNO}_{3}$ uptake for NAT and STS indicates how well CALIOP PSCs in the various composition classes conform to expected temperature existence regimes and also offers some insight into PSC growth kinetics. Figure 2 shows theoretical gas-phase $\mathrm{HNO}_{3}$ uptake curves assuming thermodynamic equilibrium conditions for STS (Carslaw et al., 1995) and NAT (Hanson and Mauersberger, 1988) at pressures of 30 and $50 \mathrm{hPa}$, assuming mixing ratios of 5 and $10 \mathrm{ppbv}$ of total $\mathrm{HNO}_{3}, 5 \mathrm{ppmv}$ of $\mathrm{H}_{2} \mathrm{O}$, and $0.1 \mathrm{ppbv} \mathrm{H}_{2} \mathrm{SO}_{4}$. The curves are presented as a function of absolute temperature in Fig. 2a and as a function of $T-T_{\text {ice }}$ in Fig. $2 \mathrm{~b}$, where $T_{\text {ice }}$ is the frost point temperature calculated using the Murphy and Koop (2005) relationship. The figure illustrates clearly that in the $T-T_{\text {ice }}$ coordinate system, the individual curves collapse into essentially single STS and NAT uptake curves, removing variations due to differences in atmospheric pressure level and local changes in $\mathrm{H}_{2} \mathrm{O}$ partial pressure (Drdla et al., 2003).

For this assessment, we examined the CALIOP PSC data record from both polar regions over the period from 2006 through 2011 and over a range of potential temperature levels spanning the $15-30 \mathrm{~km}$ altitude range. As will be discussed in Sect. 4, particle sedimentation and subsequent denitrification complicate the interpretation of the gas-phase $\mathrm{HNO}_{3}$ uptake and can also affect composition classification. As a result, data from the Antarctic, where the stratosphere is subject to severe denitrification and partial dehydration every winter, are particularly difficult to interpret. For discussion, we focus on CALIOP and MLS data from the 2009-2010 Arctic winter which complemented focused measurements from an extensive field campaign under the European Union RECONCILE (reconciliation of essential process parameters for an enhanced predictability of Arctic stratospheric
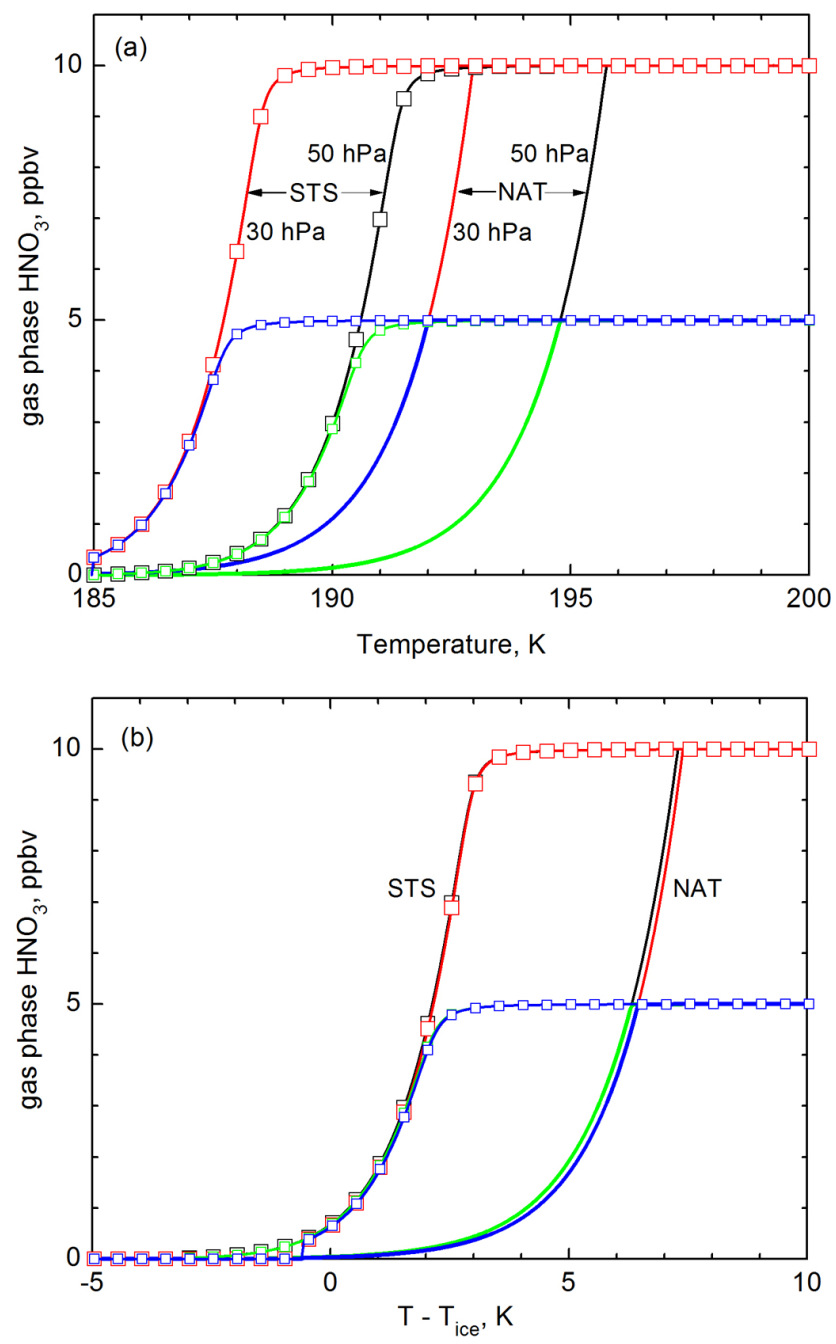

Fig. 2. Theoretical equilibrium uptake of $\mathrm{HNO}_{3}$ by STS (square symbols) and NAT as a function of (a) temperature and (b) $T-T_{\text {ice }}$. Red and black curves/symbols: 10 ppbv $\mathrm{HNO}_{3}, 5$ ppmv $\mathrm{H}_{2} \mathrm{O}$; blue and green curves/symbols: 5 ppbv $\mathrm{HNO}_{3}, 5$ ppmv $\mathrm{H}_{2} \mathrm{O}$.

ozone loss and its climate interactions) project conducted that winter from Kiruna, Sweden (P11; Dörnbrack et al., 2012). The 2009-2010 winter was characterized by unusually cold conditions in the stratosphere from mid-December through January that resulted in widespread PSCs (Dörnbrack et al., 2012; P11; Khosrawi et al., 2011). The distribution of PSCs observed by CALIOP during the 2009-2010 winter (Fig. 1) spans nearly the entire $\delta_{\text {aerosol }}$ vs. $1 / R_{532}$ measurement space with significant numbers of PSCs in all six composition classes, providing an excellent dataset for assessing the robustness of our composition classification. Although denitrification occurred during the 2009-2010 Arctic winter, average $\mathrm{HNO}_{3}$ abundances between $475-575 \mathrm{~K}$ potential temperature in January were close to $10 \mathrm{ppbv}$ (Khosrawi et al., 2011), our standard value for defining the composition boundaries. In Sect. 4, we will examine an Antarctic 

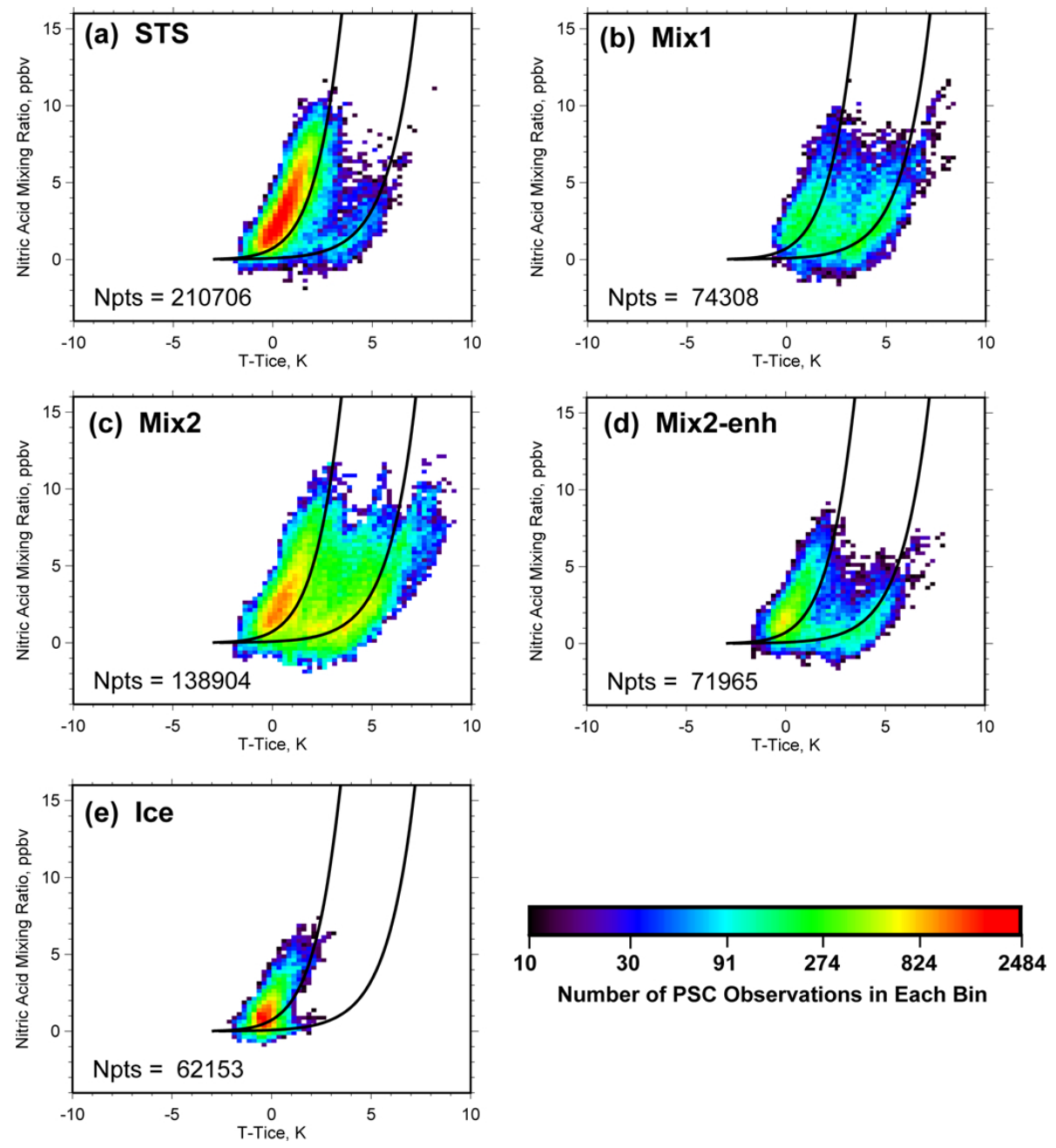

Fig. 3. Uptake of nitric acid as a function of $T-T_{\text {ice }}$ for CALIOP Arctic PSC observations at $490 \mathrm{~K}$ potential temperature during 1 December 2009-31 January 2010 for (a) STS, (b) Mix 1, (c) Mix 2, (d) Mix 2-enh, and (e) ice clouds. The histogram bin size is 0.25 ppbv $\times 0.25 \mathrm{~K}$ and the color scale indicates the number of cloud observations falling within each bin. Black lines are reference equilibrium uptake curves for STS (left) and NAT (right) assuming $16 \mathrm{ppbv} \mathrm{HNO}_{3}$ and $5 \mathrm{ppbv} \mathrm{H}_{2} \mathrm{O}$.

case to illustrate that our standard Mix 2/ice composition boundary may not be appropriate under severe denitrification/dehydration conditions.

Although the Aura MLS measurement locations and times are nearly coincident with CALIOP, the spatial resolution of the MLS gas species data is much coarser than that of the CALIOP PSC data. The ability of MLS to accurately retrieve the reduction in gas-phase $\mathrm{HNO}_{3}$ due to uptake by PSCs will depend on both the spatial extent and homogeneity of the PSC. If the roughly 4-km vertical by $400-\mathrm{km}$ horizontal MLS field of view (FOV) is not completely cloud-filled, the retrieved $\mathrm{HNO}_{3}$ value will be biased due to the influence of the higher background $\mathrm{HNO}_{3}$ in non-cloudy regions of the FOV. Based on sensitivity studies, we have restricted our analyses to scenes in which the MLS FOV is at least $75 \%$ filled with PSC observations. This is a reasonable compromise that reduces this FOV bias while at the same maintains a large ensemble of scenes for analysis.

Figure 3 shows 2-D histograms of $\mathrm{MLS} \mathrm{HNO}_{3}$ uptake vs. $T-T_{\text {ice }}$ for CALIOP PSC observations by composition class for 1 December 2009-31 January 2010 at the $490 \mathrm{~K}$ potential temperature level $(\sim 21 \mathrm{~km}) . T$ is the ambient temperature at the CALIOP observation point (from the GEOS-5 gridded analyses) and $T_{\text {ice }}$ is the frost point temperature (Murphy and Koop, 2005) calculated using the coincident Aura MLS gasphase $\mathrm{H}_{2} \mathrm{O}$ abundance. As a guide for the reader's eye, reference equilibrium uptake curves for STS and NAT are overlaid in the figures assuming total abundances of $16 \mathrm{ppbv} \mathrm{HNO}_{3}$ and 5 ppmv $\mathrm{H}_{2} \mathrm{O}$, which are representative of early December values at this level. Most observations classified as STS (Fig. 3a) are clearly aligned with the reference STS equilibrium curve, as would be anticipated since STS droplets are thought to grow fast enough to maintain equilibrium with 


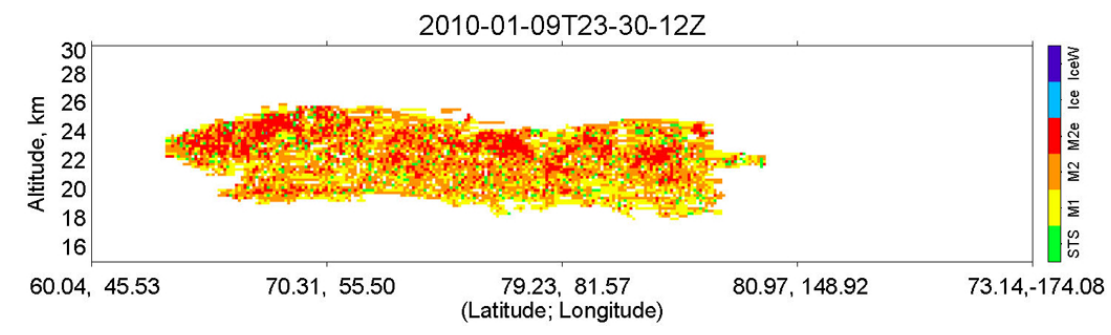

Fig. 4. Example of noise-induced misclassification in a CALIOP PSC scene from an orbit on 9 January 2010. PSC composition class is indicated by color scale at right.

the gas phase $\mathrm{HNO}_{3}$. The main STS data cluster does lie at slightly lower temperatures than the reference equilibrium curve, a finding consistent with Lambert et al. (2012) who suggested that this may be indicative of a bias in the GEOS-5 temperature data. Also of note in Fig. 3a is the secondary family of observations that lies along the reference NAT equilibrium uptake curve at temperatures too warm for STS. We interpret these points to be NAT mixtures that have been misclassified as STS because their measured $\beta_{\text {perp }}$ lies below the detection threshold for non-spherical particles due to noise. This phenomenon manifests itself in the form of "speckle" in the images of CALIOP PSC observations colorcoded by composition, as shown in Fig. 4 for an orbit track on 9 January 2010. Although the vast majority of PSC observations in this scene are classified as NAT mixtures, there is a random speckling of green (STS color code) pixels throughout the cloud, which are very likely NAT mixtures also, but have been misclassified as STS. For the 2009-2010 winter, some $5-6 \%$ of points classified as STS lie along the NAT equilibrium curve, a fraction consistent with the noiseinduced overlap in the $\beta_{\text {perp }}$ PDFs for STS and NAT mixtures as discussed earlier. It may be possible to eliminate speckle by additional averaging over altitude or by applying a spatial filter that assumes composition homogeneity over appropriately small spatial scales. We plan to investigate this in our next generation algorithm.

The $\mathrm{HNO}_{3}$ uptake as a function of $T-T_{\text {ice }}$ for PSCs classified as NAT mixtures is shown in Fig. 3b-d. The observations cover a broad range of temperatures from near $T_{\text {ice }}$ to $T_{\text {ice }}+7-8 \mathrm{~K}$, and the uptake of $\mathrm{HNO}_{3}$ for each of the NAT mixture classes exhibits two distinct modes. We interpret the mode that is closely aligned with the STS equilibrium curve to represent air parcels with relatively brief exposure to temperatures below the NAT existence temperature, $T_{\mathrm{NAT}}$. These parcels contain NAT particles that produce a detectable enhancement in $\beta_{\text {perp }}$, but the uptake of $\mathrm{HNO}_{3}$ is dominated by the much more numerous liquid droplets at lower temperatures. For these mixtures, the CALIOP $\beta_{\text {perp }}$ signal is more sensitive to the presence of the NAT particles than the MLS gas-phase $\mathrm{HNO}_{3}$ uptake observations. The second mode of NAT mixture observations is more closely aligned with the NAT equilibrium $\mathrm{HNO}_{3}$ uptake curve. We interpret this sec- ond mode to represent parcels that have been exposed to temperatures below $T_{\mathrm{NAT}}$ for extended periods of time, allowing a larger fraction of the gas-phase $\mathrm{HNO}_{3}$ to condense onto the NAT particles and bringing the mixture closer to NAT equilibrium. To explore these two NAT mixture modes further, we have examined the temperature histories along ten-day backward isentropic trajectories initiated at a subset (every fifth point horizontally and every third point vertically) of CALIOP PSC observation points in Fig. 3a-d. The trajectories were produced using the Chemical Lagrangian Model of the Stratosphere (CLaMS) (McKenna et al., 2002) with wind and temperature fields from the European Center for Medium-range Weather Forecasts (ECMWF) analyses. From these temperature histories, we are able to estimate the time the air parcel arriving at each CALIOP PSC observation point was exposed to temperatures below $T_{\mathrm{NAT}}$. The average exposure time for all of the CALIOP PSC observations that fall in each $0.25 \mathrm{ppbv} \times 0.25 \mathrm{~K}$ histogram bin is shown in Fig. 5. The results of Fig. 5 clearly indicate that NAT mixture observations that occur along the NAT equilibrium curve have been exposed to temperatures below $T_{\mathrm{NAT}}$ for much longer time periods than the non-equilibrium NAT mixtures that fall along the STS equilibrium curve, thus supporting our interpretation of Fig. 3.

We also considered two other sources of uncertainty that could impact the uptake analyses shown in Fig. 3. One is the variability in PSC composition over the MLS FOV, which we addressed by analyzing the subset of scenes in which the MLS FOV was $>75 \%$ filled with PSC observations and at least $2 / 3$ of those observations were of a single PSC composition. The $\mathrm{HNO}_{3}$ uptake plots for this subset of scenes were very similar to those in Fig. 3, leading us to the conclusion that the nature of the uptake plots is not an artifact of composition inhomogeneity. We also considered the impact of MLS and GEOS-5 measurement uncertainties. Uncertainty in $\mathrm{MLS}_{\mathrm{HNO}}$ coupled with the FOV bias accounts for no more than 1-2 ppbv of the spread in data points along the $\mathrm{HNO}_{3}$ axis in Fig. 3. Uncertainty in MLS $\mathrm{H}_{2} \mathrm{O}$ and GEOS5 temperatures produces $\sim \pm 1 \mathrm{~K}$ spread in data points along the $T-T_{\text {ice }}$ axis. Therefore, neither of these can explain the separation of data points into distinct families along the STS 

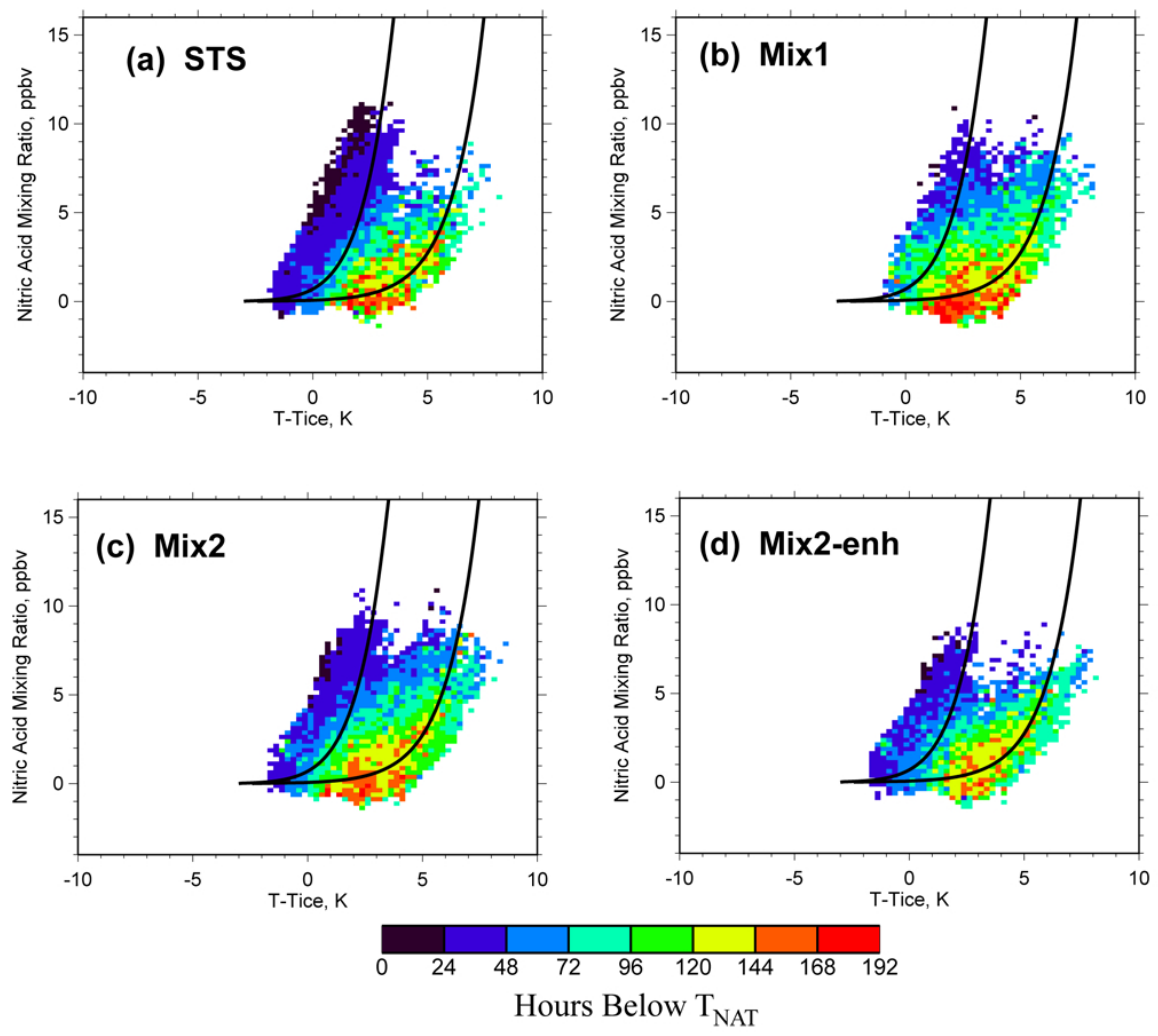

Fig. 5. Temperature histories for CALIOP Arctic PSC observations at $490 \mathrm{~K}$ potential temperature during 1 December 2009-31 January 2010 for (a) STS, (b) Mix 1, (c) Mix 2, (d) Mix 2-enh. The histogram bin size is $0.25 \mathrm{ppbv} \times 0.25 \mathrm{~K}$ and the color scale indicates the average number of hours each air parcel associated with CALIOP PSC observations falling within each bin was exposed to temperatures below $T_{\mathrm{NAT}}$. Black lines are reference equilibrium uptake curves for STS (left) and NAT (right) assuming 16 ppbv $\mathrm{HNO}_{3}$ and 5 ppbv $\mathrm{H}_{2} \mathrm{O}$.

and NAT equilibrium curves, which we have interpreted as a manifestation of a real difference in PSC growth kinetics.

The $\mathrm{HNO}_{3}$ uptake for observations identified as ice PSCs during the 2009-2010 Arctic winter is shown in Fig. 3e. Ice PSCs are expected to occur only at temperatures near and below $T_{\text {ice }}$, with almost complete uptake of gas-phase $\mathrm{HNO}_{3}$ by STS (and/or NAT) prior to the temperature having reached $T_{\text {ice. }}$. In the CALIOP observations, there is a clear maximum in ice PSCs at temperatures near or below $T_{\text {ice }}$ and $\mathrm{HNO}_{3}$ values below 2 ppbv, but ice observations also extend to temperatures above $T_{\text {ice }}$ and larger $\mathrm{HNO}_{3}$ abundances. Although this would appear to be a misclassification, i.e., ice PSCs occurring at temperatures outside their expected thermodynamic existence regime, we are confident that the ice classification is correct since the large optical signal (both $R_{532}$ and $\beta_{\text {perp }}$ ) produced by ice PSCs is a robust signature. The anomalous points in Fig. $3 \mathrm{e}$ are likely caused by differences in measurement resolution among CALIOP, GEOS-5, and MLS. Prior to mid-January, the vast majority of ice PSCs were associated with orographic wave events that occurred on relatively small spatial scales (e.g., P11). With the high spatial resolution sampling of CALIOP and the inherently large scattering ratio values associated with ice PSCs, moun- tain wave ice PSCs are easily detected and properly classified by CALIOP at the highest PSC resolution $(5 \mathrm{~km} \times 180 \mathrm{~m})$. However, given the relatively coarse resolution of both the GEOS-5 gridded analyses and Aura MLS $\mathrm{HNO}_{3}$ measurements, small scale wave features are more difficult to fully resolve. The amplitude of the temperature perturbations associated with these waves is typically underestimated in the GEOS-5 gridded analyses, and the localized uptake of $\mathrm{HNO}_{3}$ by the STS in the cold phase of the waves will be underestimated by MLS. To illustrate this point further, gas-phase $\mathrm{HNO}_{3}$ uptake associated with CALIOP ice PSCs for the periods 1-15 January 2010 and 16-31 January 2010 are shown in Fig. 6. The ice observations at anomalously warm temperatures and relatively large $\mathrm{HNO}_{3}$ mixing ratios are primarily confined to the first two weeks of January when mountain waves were the main forcing mechanism for ice cloud formation. After about 15 January, ice PSCs were observed on much larger spatial scales associated with synoptic-scale regions of temperatures below the frost point, and both GEOS5 and MLS are able to better resolve such features.

Histograms of PSC occurrence vs. $T-T_{\text {ice }}$ for 1 December 2009-31 January 2010 are depicted in Fig. 7a for all CALIOP composition classes shown in Fig. 3. These were 
(a) 1-15 January 2010

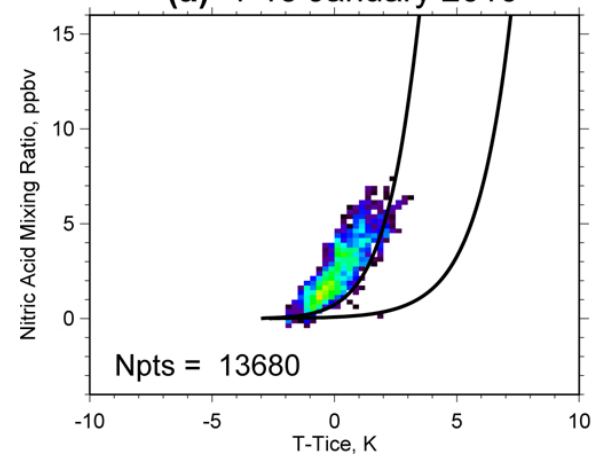

(b) 16-31 January 2010

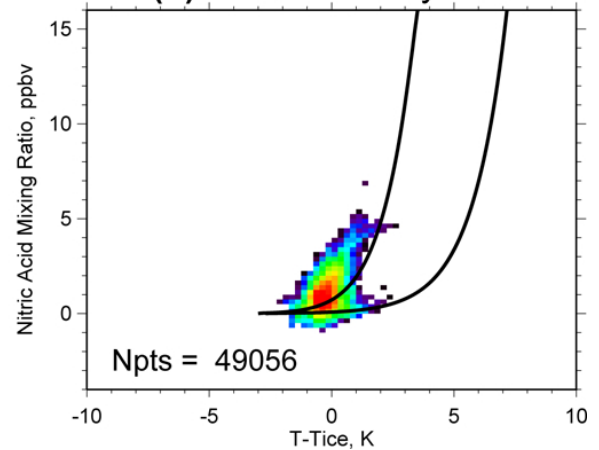

Fig. 6. $\mathrm{HNO}_{3}$ uptake as a function of $T-T_{\text {ice }}$ for CALIOP ice PSC observations during (a) 1-15 January 2010 and (b) 16-31 January 2010. Orographic waves were the primary forcing mechanism for ice PSCs during 1-15 January, while larger-scale synoptic cooling formed ice PSCs during 16-31 January. The color scale is the same as in Fig. 3.
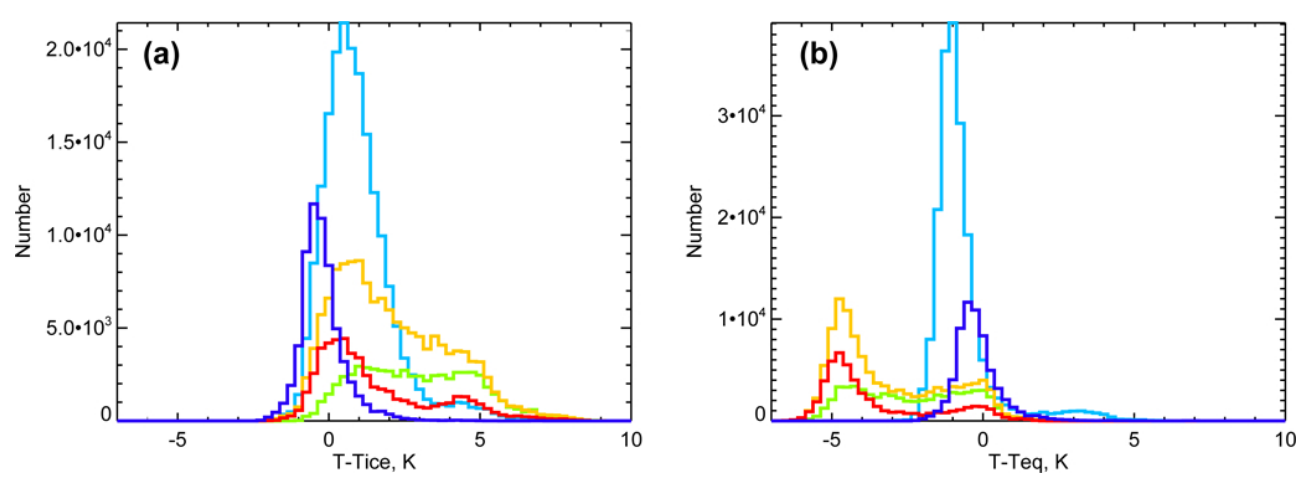

Fig. 7. Histograms of CALIOP PSC observations at $490 \mathrm{~K}$ potential temperature during 1 December 2009-31 January 2010 as a function of (a) $T-T_{\text {ice }}$ and (b) $T-T_{\text {eq }}$ by composition: STS (light blue), Mix 1 (green), Mix 2 (orange), Mix 2-enh (red), and ice (dark blue).

produced from Fig. 3 by simply summing observations over $\mathrm{HNO}_{3}$ bins. For compositions other than ice, the histograms are restricted to observations with $\mathrm{HNO}_{3}$ values greater than $1 \mathrm{ppbv}$ to avoid the region where the NAT and STS equilibrium curves converge. The behavior of the ice PSC class can be assessed directly from Fig. 7a. The mode of the ice PSC distribution is centered at a temperature slightly below the frost point (also consistent with Lambert et al. 2012) with a full-width-half-maximum of about $1 \mathrm{~K}$. The longer positive tail in the ice PSC distribution is due to warm biased temperatures associated with the wave ice events. To properly assess composition classes other than ice, a transformation to $T-T_{\text {eq }}$ is required. $T_{\text {eq }}$ is defined as $T_{\text {ice }}$, $T_{\mathrm{NAT}}$, or $T_{\mathrm{STS}}$, depending on the PSC composition classification, and is calculated using the Murphy and Koop (2005) $\left(T_{\text {ice }}\right)$, Hanson and Mauersberger (1988) $\left(T_{\mathrm{NAT}}\right)$, and Carslaw et al. (1995) ( $\left.T_{\mathrm{STS}}\right)$ relationships with the coincident MLS $\mathrm{HNO}_{3}$ and $\mathrm{H}_{2} \mathrm{O}$ abundances. Histograms of PSC occurrence vs. $T-T_{\text {eq }}$ for 1 December 2009-31 January 2010 are depicted in Fig. $7 \mathrm{~b}$ (note that other than the change in scale, the ice PSC distribution is unchanged from Fig. 7a). STS PSCs occur over a relative narrow temperature range cen- tered about $1 \mathrm{~K}$ below the STS equilibrium temperature except for the positive tail in the distribution due to speckle. The peak at $1 \mathrm{~K}$ below equilibrium may be an indication of a cold bias in the GEOS-5 temperature analyses as noted by Lambert et al. (2012). The distribution of each NAT mixture class is bimodal with one mode near the NAT equilibrium temperature and a second, more populous mode at $4-5 \mathrm{~K}$ below NAT equilibrium - which is very near the STS mode in $T-T_{\text {ice }}$ space (Fig. 7a). As mentioned earlier in the discussion of Figs. 3 and 5, this bimodality is a consequence of different exposure times to temperatures below $T_{\mathrm{NAT}}$. The fact that the NAT mixture histograms are distinctly bimodal, i.e., the mixtures do not occur uniformly over the space between $T_{\mathrm{NAT}}$ and $T_{\mathrm{STS}}$, is quite interesting and may indicate a rapid switch from the thermodynamically metastable STS to stable NAT after sufficient time below $T_{\mathrm{NAT}}$.

Histograms of PSC occurrence vs. $T-T_{\text {ice }}$ and $T-T_{\text {eq }}$ for five seasons in the Arctic (2006-2011) are shown in Fig. 8. These multi-year histograms are similar in nature to as those for the 2009-2010 Arctic season (Fig. 7), with observations in all composition classes conforming to expected thermodynamic existence regimes. The notable exceptions again are 

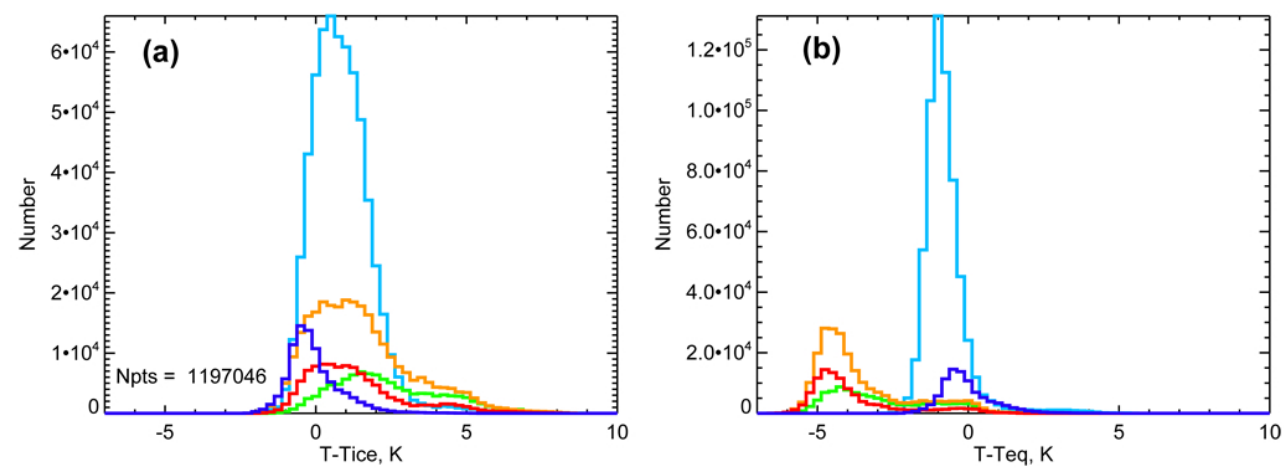

Fig. 8. Histograms of CALIOP PSC observations at $490 \mathrm{~K}$ potential temperature during five Arctic winters (2006-2011) as a function of (a) $T-T_{\text {ice }}$ and (b) $T-T_{\text {eq }}$ by composition: STS (light blue), Mix 1 (green), Mix 2 (orange), Mix 2-enh (red), and ice (dark blue).
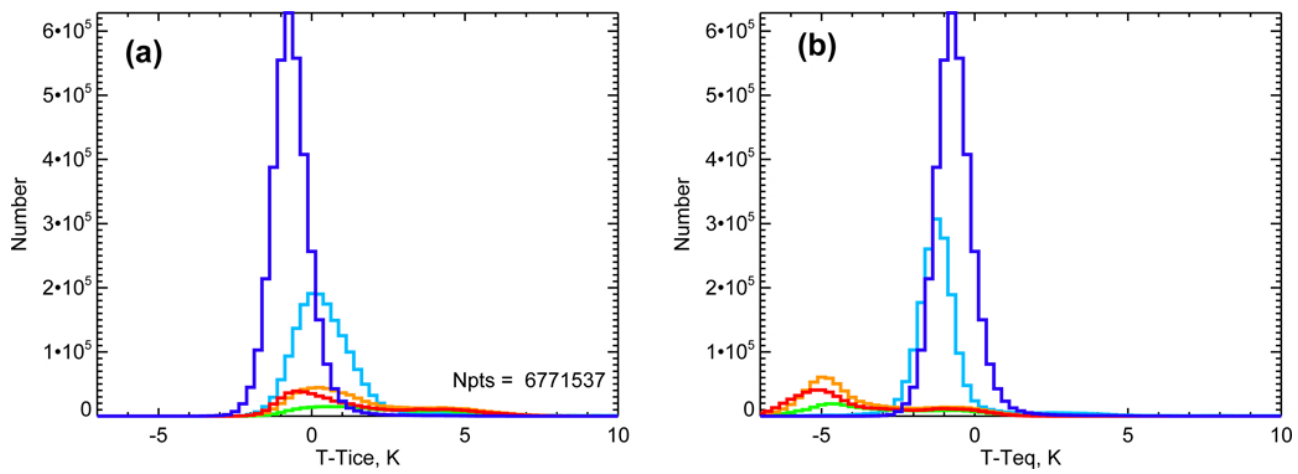

Fig. 9. Histograms of CALIOP PSC observations at $490 \mathrm{~K}$ potential temperature from six Antarctic winters (2006-2011) as a function of (a) $T-T_{\text {ice }}$ and (b) $T-T_{\text {eq }}$ by composition: STS (light blue), Mix 1 (green), Mix 2 (orange), Mix 2-enh (red), and ice (dark blue).

observations classified as STS at anomalously warm temperatures, which are likely NAT clouds misclassified due to noise in $\beta_{\text {perp }}$ (speckle) and the ice PSCs at (apparent) temperatures above the frost point, which are associated with orographic waves, the predominant mechanism for ice PSC formation in the Arctic. Histograms of PSC occurrence vs. $T-T_{\text {ice }}$ and $T-T_{\text {eq }}$ for six seasons in the Antarctic (20062011) are shown in Fig. 9. Although less pronounced than in the Arctic, a small number of anomalously warm STS points also appear in the Antarctic STS histogram. Ice PSC formation in the Antarctic occurs more frequently and generally on larger spatial scales than in the Arctic and as a consequence ice PSC observations at (apparent) temperatures above the frost point are less common. These multi-year histograms represent approximately 1.2 million Arctic and 6.8 million Antarctic PSC observations and provide confidence that the $\mathrm{P} 09 / \mathrm{P} 11$ composition classification is producing results that are consistent with theoretical expectations for each composition class.

\section{Impact of denitrification on composition classification}

The composition class boundaries defined by P09 and P11 are based on a standard set of conditions: $50 \mathrm{hPa}$ atmospheric pressure and nominal mixing ratios of $10 \mathrm{ppbv} \mathrm{HNO}_{3}$ and 5 ppmv $\mathrm{H}_{2} \mathrm{O}$. For most Arctic winters and early in the Antarctic winter, these values are representative. However, the Antarctic is subject to severe denitrification and partial dehydration every winter, with $\mathrm{HNO}_{3}$ being nearly totally depleted at times in the interior of the vortex. These extreme conditions can have a significant impact on the location of the boundary between ice and NAT mixture (Mix 2 and Mix 2enh) PSC domains. Shown in Fig. 10a are theoretical calculations of CALIOP optical signals for various liquid/NAT mixtures and ice computed for the standard conditions (10 ppbv $\mathrm{HNO}_{3}$ ). The ice PSCs, which are assumed to form from fully developed STS, are the arm of points extending up and to the right from the STS domain at $1 / R_{532} \sim 0.2$. For comparison, Fig. 10b depicts theoretical calculations for denitrified conditions of $5 \mathrm{ppbv} \mathrm{HNO}_{3}$. The reduction in available condensable $\mathrm{HNO}_{3}$ limits the growth potential of the STS and NAT particles, resulting in a systematic shift of the optical signals from STS and NAT mixtures to smaller scattering ratios (larger $1 / R_{532}$ ) values. For these denitrified conditions, 

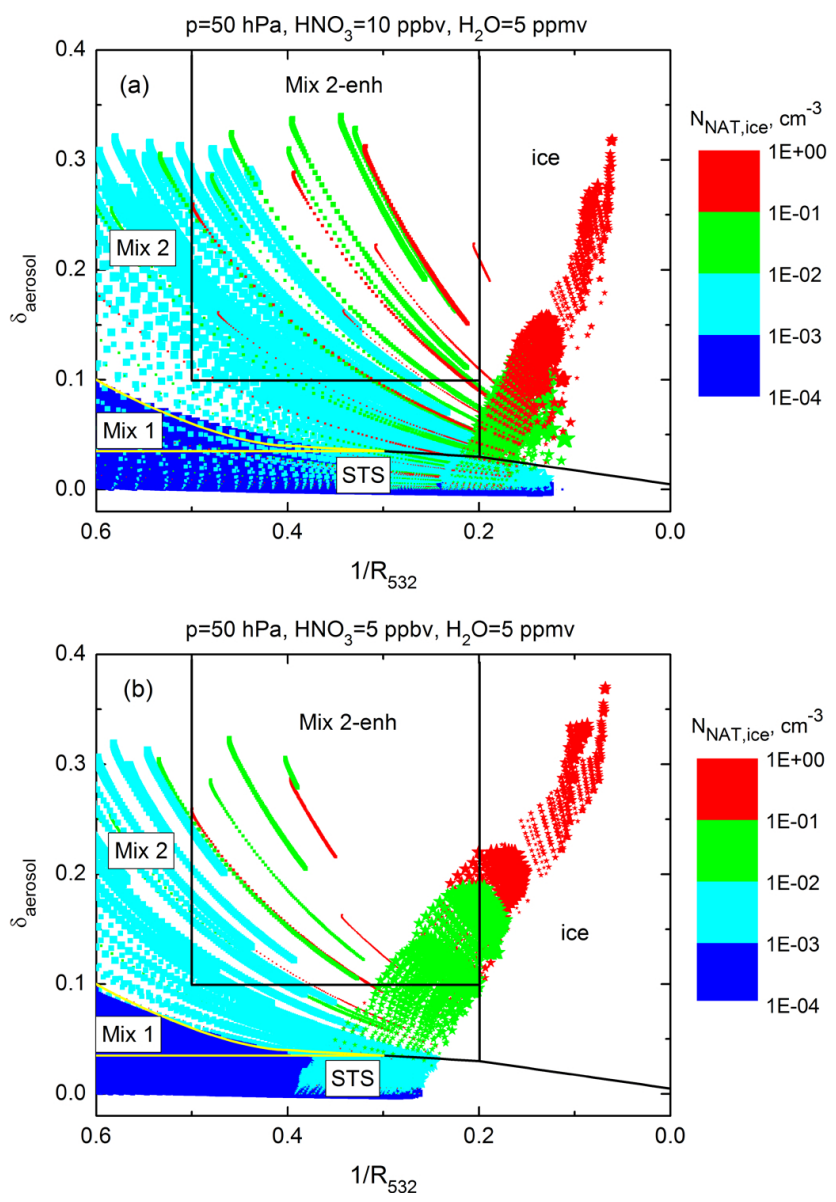

Fig. 10. Theoretical calculations of CALIOP optical signals for various liquid/NAT mixtures and ice computed for the (a) standard and (b) denitrified conditions. Points are color-coded by particle number densities as indicated in scale on right.

STS only extends to $1 / R_{532}$ values of $\sim 0.3$ and as a result the location of the departure of the arm of ice points from the STS domain is shifted to the left. Therefore, to properly account for denitrification in our composition classification scheme, the boundary between ice and NAT mixture (Mix 2 and Mix 2-enh) PSC domains should be shifted to smaller scattering ratio values (larger $1 / R_{532}$ values). The magnitude of the shift is a function of the total abundance of $\mathrm{HNO}_{3}$.

The effects of denitrification can also clearly be seen in the CALIOP PSC observations. For example, shown in Fig. 11a is the distribution of PSCs observed by CALIOP for June 2009 in an equivalent latitude band between $60^{\circ} \mathrm{S}$ and $70^{\circ} \mathrm{S}$. The total $\mathrm{HNO}_{3}$ mixing ratio during June was decreasing as denitrification began, but on average was close to our standard value of 10 ppbv. The period was dominated by fully developed STS (maximum along the $\delta_{\text {aerosol }}=0$ axis) and ice PSCs, with a small number of mixtures. Similar to the theoretical calculations (Fig. 10a), the arm of ice PSC observations (dashed white line) departs from the STS maximum at $1 / R_{532}$ values of 0.2 . In contrast, Fig. $11 \mathrm{~b}$ depicts
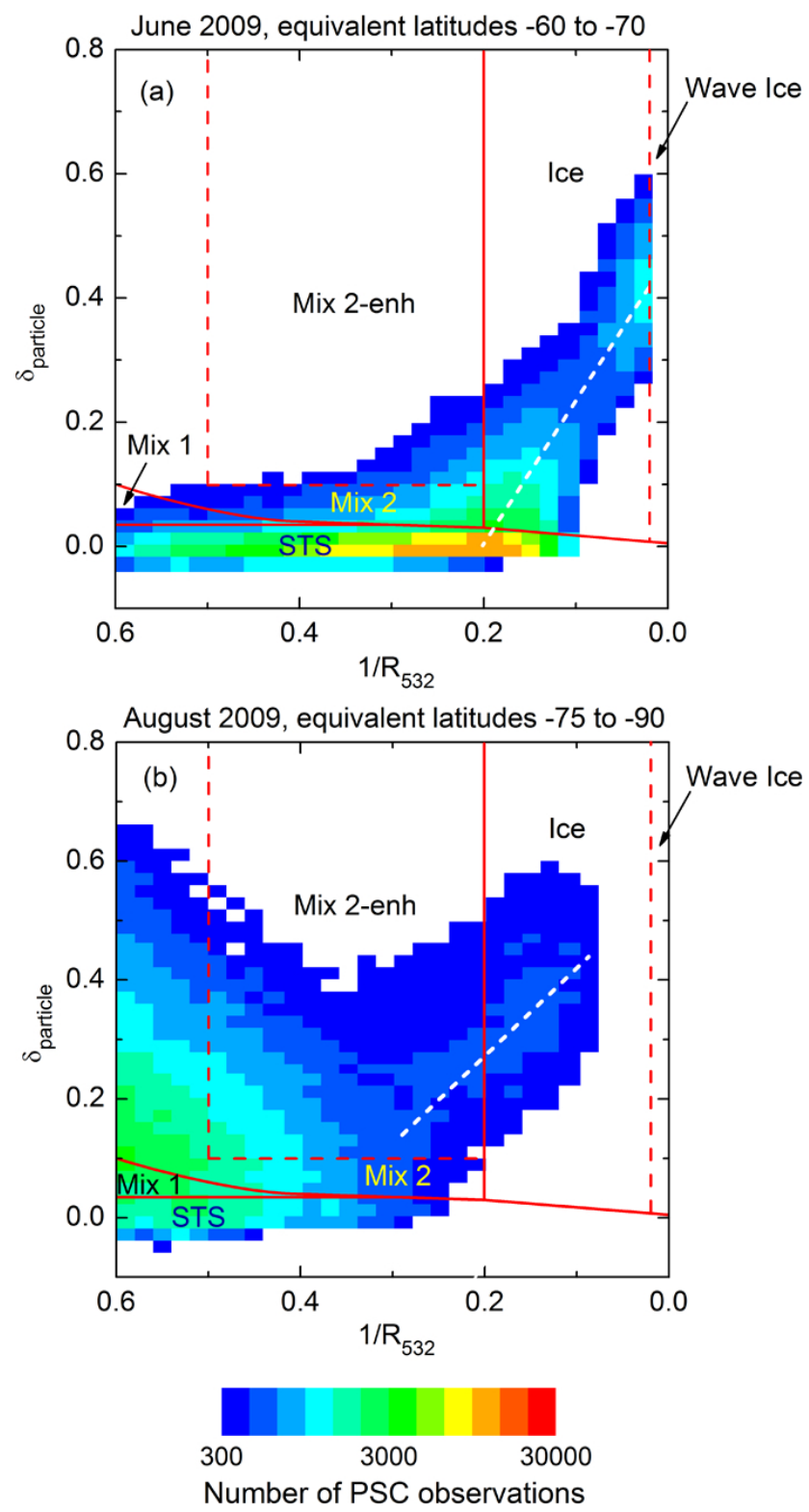

Fig. 11. Distribution of CALIOP PSC observations for (a) June and (b) August 2009 in selected equivalent latitude bands as indicated at the top of each panel. The colors represent the density of the PSC observations in each bin relative to the maximum. The white dashed lines indicate the axis of the ice PSC observations. The bin size is $0.02 \times 0.02$ (both unitless).

CALIOP observations in August 2009 deep inside the vortex at equivalent latitudes between $75^{\circ} \mathrm{S}$ and $90^{\circ} \mathrm{S}$. The total $\mathrm{HNO}_{3}$ abundance at this time had dropped significantly from early season values to around $5 \mathrm{ppbv}$ or less limiting the growth of the STS and NAT particles and resulting in a discernible shift in the point where the axis of the ice arm departs from the STS mode to a $1 / R_{532}$ value of about 0.3 (similar to Fig. 10b). 

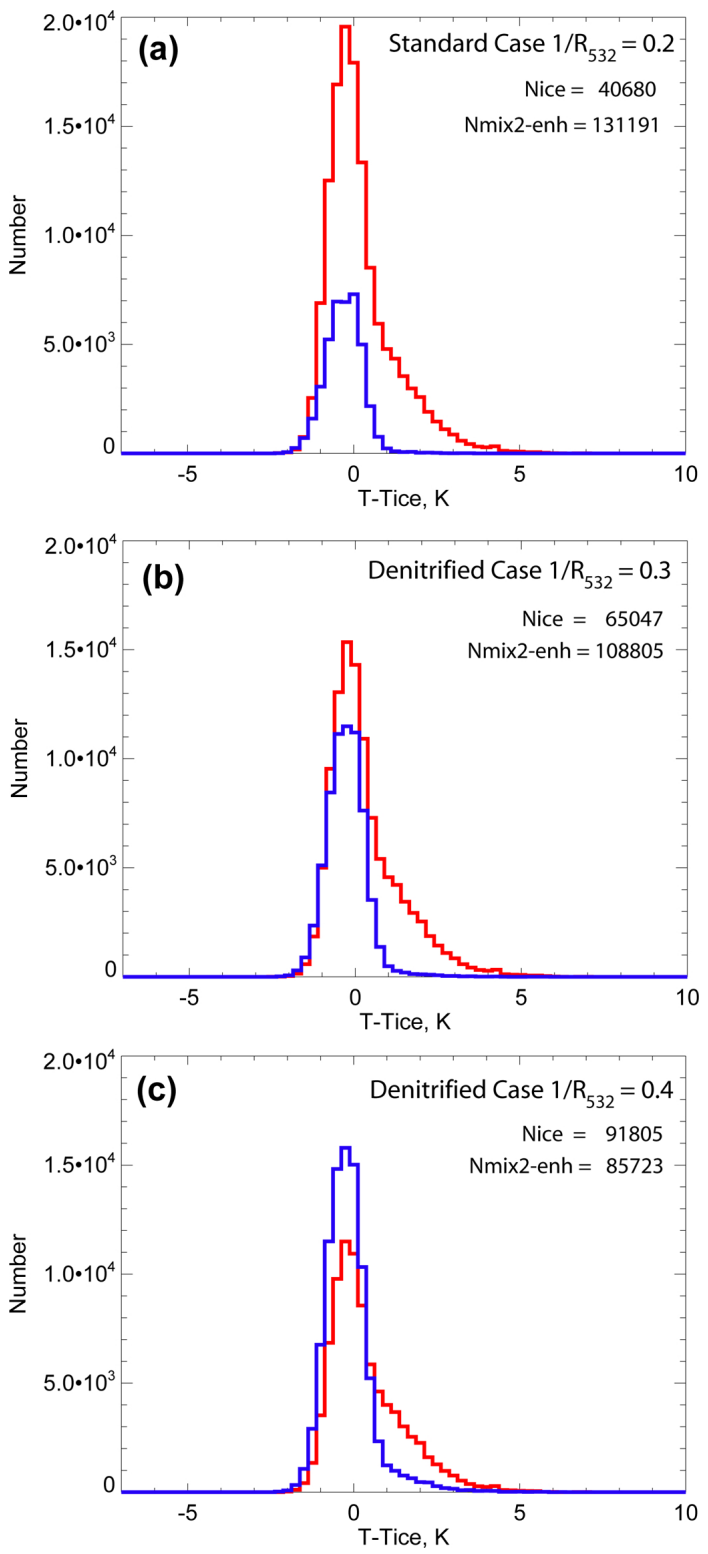

Fig. 12. PDFs of ice (blue) and Mix 2-enh (red) PSC observations in the $75-90^{\circ} \mathrm{S}$ equivalent latitude band for August 2009 as a function of $T-T_{\text {ice }}$ using an ice/mix 2-enh boundary of (a) $1 / R_{532}=0.2$, (b) $1 / R_{532}=0.3$, and (c) $1 / R_{532}=0.4$.

The implication from Figs. 10 and 11 is that some ice PSCs are being misclassified as NAT mixtures during periods of moderate to severe denitrification, which primarily occur in the Antarctic. To explore this possibility, we examine in more detail the ice and Mix 2 PSC observations from the August 2009 period in the Antarctic. Histograms of ice and Mix 2enh PSC occurrence as a function of $T-T_{\text {ice }}$ from the interior of the vortex in August 2009 are shown in Fig. 12. Figure 12a depicts histograms for composition classification using our standard ice/Mix 2-enh boundary $\left(1 / R_{532}=0.2\right)$. With random measurement noise and no bias in temperature or $T_{\text {ice }}$, one would expect the ice PSC histogram to be Gaussian with a mode at $T-T_{\text {ice }}=0$. The mode of the actual histogram is slightly below the frost point, but the positive tail of the distribution appears to be truncated relative to the negative tail. The Mix 2-enh distribution also has a maximum near the frost point, some of which may be misclassified ice, but also extends to warmer temperatures as would be expected for NAT mixtures. To account for denitrification in our composition classification, we should shift the ice/Mix 2enh boundary appropriately based on the total abundance of $\mathrm{HNO}_{3}$. To demonstrate this, Fig. 12b shows histograms for composition classification using an ice/Mix 2-enh boundary of $1 / R_{532}=0.3$. For this case, there has been a redistribution of compositions with over a $50 \%$ increase in the number of ice clouds, which had been classified as Mix 2-enh in our standard case. The shape of the ice PSC distribution in this case appears to be more Gaussian-like than in the standard case, with no obvious truncation of the positive tail. Figure $12 \mathrm{c}$ shows histograms for composition classification using an ice/Mix 2-enh boundary of $1 / R_{532}=0.4$. This results in more than a doubling of the number of ice PSCs relative to the standard case, but the ice PSC distribution now shows a noticeable extension to warmer temperatures $\left(T_{\text {ice }}+3 \mathrm{~K}\right)$, indicating that the boundary has been shifted too far to the left with some Mix 2-enh clouds now being misclassified as ice. In practice, it will be difficult to accurately account for the magnitude of denitrification since most $\mathrm{HNO}_{3}$ measurements are gas phase only and are impacted by uptake on PSC particles. One possible option would be to produce a "cloud-free" MLS $\mathrm{HNO}_{3}$ dataset using the CALIOP PSC observations to filter out Aura MLS measurements that may be impacted by uptake by PSC particles.

\section{Summary and future direction}

We have used Aura MLS gas phase $\mathrm{HNO}_{3}$ and $\mathrm{H}_{2} \mathrm{O}$ measurements along with GEOS-5 temperature analyses to independently assess the CALIOP PSC composition classification scheme, which is based solely on the lidar optical measurements. Our approach was to examine the uptake of $\mathrm{HNO}_{3}$ as a function of $T-T_{\text {ice }}$ to determine if the assigned PSC composition is consistent with the thermodynamic existence regimes for STS, NAT, and ice. MLS $\mathrm{HNO}_{3}$ values will be biased when the PSCs only partially fill the instrument's FOV. To reduce this bias, we limited our analyses to scenes in which the MLS FOV is at least $75 \%$ filled with PSC observations.

PSCs identified as STS exhibit gas phase uptake of $\mathrm{HNO}_{3}$ consistent with theory, but with a small temperature bias, consistent with previous studies. Some $(\sim 6 \%)$ of points being classified as STS are actually liquid/NAT mixtures whose $\beta_{\text {perp }}$ falls below the NAT mixture detection threshold due to negative noise excursions. This phenomenon commonly 
appears as random speckle of STS pixels in an otherwise NAT mixture cloud.

PSCs identified as NAT mixtures exhibit two distinct preferred modes of $\mathrm{HNO}_{3}$ uptake: a non-equilibrium mode that is closely aligned with the STS $\mathrm{HNO}_{3}$ uptake curve and a second mode that is more closely aligned with the NAT equilibrium $\mathrm{HNO}_{3}$ uptake curve. Trajectory analyses show that NAT mixtures in the non-equilibrium mode have been below $T_{\mathrm{NAT}}$ for only short periods of time. Since the growth of NAT particles is kinetically limited, the $\mathrm{HNO}_{3}$ uptake in these mixtures is dominated by the STS droplets. On the other hand, NAT mixtures in the second mode have been below $T_{\mathrm{NAT}}$ for much longer periods of time allowing the thermodynamically favored NAT particles to approach equilibrium.

Ice PSC classification is robust in the CALIOP optical data, and the mode in the ice observations occurs about $0.5 \mathrm{~K}$ below the frost point. The anomalously warm temperatures and high $\mathrm{HNO}_{3}$ values associated with CALIOP observations of small-scale ice clouds, such as orographic wave clouds, are a result of these small scale features not being fully resolved in the GEOS-5 and MLS observations.

We also demonstrated that severe denitrification can impact the CALIOP classification of ice and Mix 2-enh PSCs. The P09/P11 composition classification places the Mix 2enh/ice boundary at the maximum expected value of $R_{532}$ for fully developed STS $\left(R_{532}=5\right)$, from which ice is assumed to evolve. Denitrification reduces the growth potential of the STS particles and, hence, the maximum $R_{532}$ value observed in fully developed STS. To properly account for denitrification, the Mix 2-enh/ice boundary should be shifted appropriately to smaller $R_{532}$ values. Since the P09/11 scheme uses a fixed Mix 2-enh/ice boundary, some ice PSCs are being misclassified as NAT mixtures during periods of moderate to severe denitrification, primarily in the Antarctic.

With the few notable exceptions discussed above, the $\mathrm{P} 09 / \mathrm{P} 11$ composition classification is producing results that are consistent with theoretical expectations for each composition class. We have a good understanding of the cause of the minor misclassifications that do occur and will investigate means to correct these deficiencies in our next generation algorithm.

Acknowledgements. The Aura MLS gas species data and Derived Meteorological Products (DMP) were provided courtesy of the MLS team and obtained through the Aura MLS website (http://mls.jpl.nasa.gov/index-eos-mls.php). We would like to thank Ines Engel (ETH Zurich) and Jens-Uwe Grooß (Forschungszentrum Jülich) for providing CLaMS trajectory analyses and temperature histories. We would also like to thank David Considine, Program Scientist for the CALIPSO/CloudSat Missions for continued support of this research. Support for L. Poole is provided under NASA contract NNL11AA10D. Work at the Jet Propulsion Laboratory, California Institute of Technology, was carried out under a contract with the National Aeronautics and Space Administration. The work of I. Engel and J.-U. Grooß was supported by the EC as part of the FP7 project RECONCILE (Grant number: RECONCILE-226365-FP7-ENV-2008-1).

Edited by: F. Khosrawi

\section{References}

Biele, J., Tsias, A., Luo, B. P., Carslaw, K. S., Neuber, R., Beyerle, G., and Peter, T.: Nonequilibrium coexistence of solid and liquid particles in Arctic stratospheric clouds, J. Geophys. Res., 106, 22991-23007, 2001.

Cairo, F., Di Donfrancesco, G., Adriani, A., Pulvirenti, L., and Fierli, F.: Comparison of various linear depolarization parameters measured by lidar, Appl. Optics, 38, 4425-4432, 1999.

Carslaw, K. S., Luo, B. P., and Peter, T.: An analytic expression for the composition of aqueous $\mathrm{HNO}_{3}-\mathrm{H}_{2} \mathrm{SO}_{4}$ stratospheric aerosols including gas phase removal of $\mathrm{HNO}_{3}$, Geophys. Res. Lett., 22, 1877-1880, 1995.

Dörnbrack, A., Pitts, M. C., Poole, L. R., Orsolini, Y. J., Nishii, K., and Nakamura, H.: The 2009-2010 Arctic stratospheric winter general evolution, mountain waves and predictability of an operational weather forecast model, Atmos. Chem. Phys., 12, 36593675, doi:10.5194/acp-12-3659-2012, 2012.

Drdla, K., Gandrud, B. W., Baumgardner, D., Wilson, J. C., Bui, T. P., Hurst, D., Schauffler, S. M., Jost, H., Greenblatt, J. B., and Webster, C. R.: Evidence for the widespread presence of liquidphase particles during the 1999-2000 Arctic winter, J. Geophys. Res., 108, 8318, doi:10.1029/2001JD001127, 2003.

Fueglistaler, S., Buss, S., Luo, B. P., Wernli, H., Flentje, H., Hostetler, C. A., Poole, L. R., Carslaw, K. S., and Peter, Th.: Detailed modeling of mountain wave PSCs, Atmos. Chem. Phys., 3, 697-712, doi:10.5194/acp-3-697-2003, 2003.

Hanson, D. R. and Mauersberger, K.: Laboratory studies of the nitric acid trihydrate: Implications for the south polar stratosphere, Geophys. Res. Lett., 15, 855-858, 1988.

Höpfner, M., Pitts, M. C., and Poole, L. R.: Comparison between CALIPSO and MIPAS observations of polar stratospheric clouds, J. Geophys. Res., 114, D00H05, doi:10.1029/2009JD012114, 2009.

Hunt, W. H., Winker, D. M., Vaughan, M. A., Powell, K. A., Lucker, P. L., and Weimer, C.: CALIPSO Lidar Description and Performance Assessment, J. Atmos. Ocean. Tech., 26, 1214-1228, doi:10.1175/2009JTECHA1223.1, 2009.

Khosrawi, F., Urban, J., Pitts, M. C., Voelger, P., Achtert, P., Kaphlanov, M., Santee, M. L., Manney, G. L., Murtagh, D., and Fricke, K.-H.: Denitrification and polar stratospheric cloud formation during the Arctic winter 2009/2010, Atmos. Chem. Phys., 11, 8471-8487, doi:10.5194/acp-11-8471-2011, 2011.

Lambert, A., Read, W. G., Livesey, N. J., Santee, M. L., Manney, G. L., Froidevaux, L., Wu, D. L., Schwartz, M. J., Pumphrey, H. C., Jimenez, C., Nedoluha, G. E., Cofield, R. E., Cuddy, D. T., Daffer, W. H., Drouin, B. J., Fuller, R. A., Jarnot, R. F., Knosp, B. W., Pickett, H. M., Perun, V. S., Snyder, W. V., Stek, P. C., Thurstans, R. P., Wagner, P. A., Waters, J. W., Jucks, K. W., Toon, G. C., Stachnik, R. A., Bernath, P. F., Boone, C. D., Walker, K. A., Urban, J., Murtagh, D., Elkins, J. W., and Atlas, E.: Validation of the Aura Microwave Limb Sounder middle atmosphere water 
vapor and nitrous oxide measurements, J. Geophys. Res., 112, D24S36, doi:10.1029/2007JD008724, 2007.

Lambert, A., Santee, M. L., Wu, D. L., and Chae, J. H.: A-train CALIOP and MLS observations of early winter Antarctic polar stratospheric clouds and nitric acid in 2008, Atmos. Chem. Phys., 12, 2899-2931, doi:10.5194/acp-12-2899-2012, 2012.

Livesey, N. J., Snyder, W. V., Read, W. G., and Wagner, P. A.: Retrieval algorithms for the EOS Microwave Limb Sounder (MLS), IEEE T. Geosci. Remote, 44, 1144-1155, 2006.

Livesey, N. J., Read, W. G., Froidevaux, L., Lambert, A., Manney, G. L., Pumphrey, H. C., Santee, M. L., Schwartz, M. J., Wang, S., Cofield, R. E., Cuddy, D. T., Fuller, R. A., Jarnot, R. F., Jiang, J. H., Knosp, B. W., Stek, P. C., Wagner, P. A., and Wu, D. L.: Version 3.3 Level 3 data quality and description document, Tech. Rep. JPL D-33509, Jet Propulsion Laboratory, available at: http: //mls.jpl.nasa.gov (last access: January 2013), 2011.

Lowe, D. and MacKenzie, A. R.: Polar stratospheric cloud microphysics and chemistry, J. Atmos. Sol.-Terr. Phy., 70, 13-40, 2008.

Manney, G. L., Daffer, W. H., Zawodny, J. M., Bernath, P. F., Hoppel, K. W., Walker, K. A., Knosp, B. W., Boone, C., Remsberg, E. E., Santee, M. L., Harvey, V. L., Pawson, S., Jackson, D. R., Deaver, L., McElroy, C. T., McLinden, C. A., Drummond, J. R., Pumphrey, H. C., Lambert, A., Schwartz, M. J., Froidevaux, L., McLeod, S., Takacs, L. L., Suarez, M. J., Trepte, C. R., Cuddy, D. C., Livesey, N. J., Harwood, R. S., and Waters, J. W.: Solar occultation satellite data and derived meteorological products: Sampling issues and comparisons with Aura Microwave Limb Sounder, J. Geophys. Res., 112, D24S50, doi:10.1029/2007JD008709, 2007.

McKenna, D., Konopka, P., Grooß, J., Günther, G., Müller, R., Spang, R., Offermann, D., and Orsolini, Y.: A new Chemical Lagrangian Model of the Stratosphere (CLaMS) - 1. Formulation of advection and mixing, J. Geophys. Res., 107, ACH 15-1-ACH 15-15, doi:10.1029/2000JD000114, 2002.

Murphy, D. M. and Koop, T.: Review of the vapour pressures of ice and supercooled water for atmospheric applications, Q. J. Roy. Meteor. Soc., 131, 1539-1565, doi:10.1256/qj.04.94, 2005.

Noel, V. and Pitts, M.: Gravity wave events from mesoscale simulations compared to polar stratospheric clouds observed from spaceborne lidar over the Antarctic Peninsula, J. Geophys. Res., 117, D11207, doi:10.1029/2011JD017318, 2012.

Noel, V., Hertzog, A., Chepfer, H., and Winker, D.: Polar stratospheric clouds over Antarctica from the CALIPSO spaceborne lidar, J. Geophys. Res., 113, D02205, doi:10.1029/2007JD008616, 2008.

Pitts, M. C., Thomason, L. W., Poole, L. R., and Winker, D. M.: Characterization of Polar Stratospheric Clouds with spaceborne lidar: CALIPSO and the 2006 Antarctic season, Atmos. Chem. Phys., 7, 5207-5228, doi:10.5194/acp-7-5207-2007, 2007.

Pitts, M. C., Poole, L. R., and Thomason, L. W.: CALIPSO polar stratospheric cloud observations: second-generation detection algorithm and composition discrimination, Atmos. Chem. Phys., 9, 7577-7589, doi:10.5194/acp-9-7577-2009, 2009.

Pitts, M. C., Poole, L. R., Dörnbrack, A., and Thomason, L. W.: The 2009-2010 Arctic polar stratospheric cloud season: a CALIPSO perspective, Atmos. Chem. Phys., 11, 2161-2177, doi:10.5194/acp-11-2161-2011, 2011.
Powell, K. A., Hostetler, C. A., Liu, Z., Vaughan, M. A., Kuehn, R. E., Hunt, W. H., Lee, K., Trepte, C. R., Rogers, R. R., Young, S. A., and Winker, D. M.: CALIPSO Lidar Calibration Algorithms: Part I - Nighttime $532 \mathrm{~nm}$ Parallel Channel and $532 \mathrm{~nm}$ Perpendicular Channel, J. Atmos. Ocean. Tech., 26, 2015-2033, doi:10.1175/2009JTECHA1242.1, 2009.

Read, W. G., Lambert, A., Bacmeister, J., Cofield, R. E., Christensen, L. E., Cuddy, D. T., Daffer, W. H., Drouin, B. J., Fetzer, E., Froidevaux, L., Fuller, R., Herman, R., Jarnot, R. F., Jiang, J. H., Jiang, Y. B., Kelly, K., Knosp, B. W., Kovalenko, L. J., Livesey, N. J., Liu, H. C., Manney, G. L., Pickett, H. M., Pumphrey, H. C., Rosenlof, K. H., Sabounchi, X., Santee, M. L., Schwartz, M. J., Snyder,W. V., Stek, P. C., Su, H., Takacs, L. L., Thurstans, R. P., Vomel, H., Wagner, P. A., Waters, J. W.,Webster, C. R., Weinstock, E. M., and Wu, D. L.: Aura Microwave Limb Sounder upper tropospheric and lower stratospheric $\mathrm{H}_{2} \mathrm{O}$ and relative humidity with respect to ice validation, J. Geophys. Res., 112, D24S35, doi:10.1029/2007JD008752, 2007.

Rienecker, M. M., Suarez, M. J., Todling, R., Bacmeister, J., Takacs, L., Liu, H.-C., Gu, W., Sienkiewicz, M., Koster, R. D., Gelaro, R., Stajner, I., and Nielsenand, J. E.: The GEOS-5 Data Assimilation System-Documentation of versions 5.0.1 and 5.1.0, and 5.2.0. NASA Tech. Rep. Series on Global Modeling and Data Assimilation, NASA/TM-2008-104606, Vol. 27, 92 pp., 2008.

Santee, M. L., Lambert, A., Read, W. G., Livesey, N. J., Cofield, R. E., Cuddy, D. T., Daffer, W. H., Drouin, B. J., Froidevaux, L., Fuller, R. A., Jarnot, R. F., Knosp, B. W., Manney, G. L., Perun, V. S., Snyder, W. V., Stek, P. C., Thurstans, R. P., Wagner, P. A., Waters, J. W., Muscari, G., de Zafra, R. L., Dibb, J. E., Fahey, D.W., Popp, P. J., Marcy, T. P., Jucks, K. W., Toon, G. C., Stachnik, R. A., Bernath, P. F., Boone, C. D., Walker, K. A., Urban, J., and Murtagh, D.: Validation of the Aura Microwave Limb Sounder $\mathrm{HNO}_{3}$ measurements, J. Geophys. Res., 112, D24S40, doi:10.1029/2007JD008721, 2007.

Solomon, S.: Stratospheric ozone depletion: A review of concepts and history, Rev. Geophys., 37, 275-316, 1999.

Stephens, G. L., Vane, D. G., Boain, R. J., Mace, G. G., Sassen, K., Wang, Z., Illingworth, A. J., O'Connor, E. J., Rossow, W. B., Durden, S. L., Miller, S. D., Austin, R. T., Benedetti, A., Mitrescu, C., and the CloudSat Science Team: The CloudSat mission and the A-Train: A new dimension of space-based observations of clouds and precipitation, B. Am. Meteorol. Soc., 83, 1771-1790, 2002.

Toon, O., Tabazadeh, A., Browell, E., and Jordan, J.: Analysis of lidar observations of Arctic polar stratospheric clouds during January 1989, J. Geophys. Res., 105, 20589-20615, 2000.

Waters, J. W., Froidevaux, L., Harwood, R. S., Jarnot, R. F., Pickett, H. M., Read, W. G., Siegel, P. H., Cofield, R. E., Filipiak, M. J., Flower, D. A., Holden, J. R., Lau, G. K. K., Livesey, N. J., Manney, G. L., Pumphrey, H. C., Santee, M. L., Wu, D. L., Cuddy, D. T., Lay, R. R., Loo, M. S., Perun, V. S., Schwartz, M. J., Stek, P. C., Thurstans, R. P., Boyles, M. A., Chandra, K. M., Chavez, M. C., Chen, G. S., Chudasama, B. V., Dodge, R., Fuller, R. A., Girard, M. A., Jiang, J. H., Jiang, Y. B., Oswald, J. E., Patel, N. C., Pukala, D. M., Quintero, O., Scaff, D., Van Snyder, W., Tope, M. C., Wagner, P. A., and Walch, M. J.: The Earth Observing System Microwave Limb Sounder (EOS MLS) on the Aura satellite, IEEE T. Geosci. Remote Sens., 44, 1075-1092, 2006. 
Winker, D. M., Vaughan, M. A., Omar, A. H., Hu, Y., Powell, K. A., Liu, Z., Hunt, W. H., and Young, S. A.: Overview of the CALIPSO
Mission and CALIOP Data Processing Algorithms, J. Atmos. Ocean. Tech., 26, 2310-2323, doi:10.1175/2009JTECHA1281.1, 2009. 